\title{
Review Article \\ Pathogenesis of Chronic Hyperglycemia: From Reductive Stress to Oxidative Stress
}

\begin{abstract}
Liang-Jun Yan
Department of Pharmaceutical Sciences, UNT System College of Pharmacy, University of North Texas Health Science Center, 3500 Camp Bowie Boulevard, RES-314E, Fort Worth, TX 76107, USA
\end{abstract}

Correspondence should be addressed to Liang-Jun Yan; liang-jun.yan@unthsc.edu

Received 29 April 2014; Accepted 27 May 2014; Published 16 June 2014

Academic Editor: Konstantinos Papatheodorou

Copyright (c) 2014 Liang-Jun Yan. This is an open access article distributed under the Creative Commons Attribution License, which permits unrestricted use, distribution, and reproduction in any medium, provided the original work is properly cited.

\begin{abstract}
Chronic overnutrition creates chronic hyperglycemia that can gradually induce insulin resistance and insulin secretion impairment. These disorders, if not intervened, will eventually be followed by appearance of frank diabetes. The mechanisms of this chronic pathogenic process are complex but have been suggested to involve production of reactive oxygen species (ROS) and oxidative stress. In this review, I highlight evidence that reductive stress imposed by overflux of NADH through the mitochondrial electron transport chain is the source of oxidative stress, which is based on establishments that more NADH recycling by mitochondrial complex I leads to more electron leakage and thus more ROS production. The elevated levels of both NADH and ROS can inhibit and inactivate glyceraldehyde 3-phosphate dehydrogenase (GAPDH), respectively, resulting in blockage of the glycolytic pathway and accumulation of glycerol 3-phospate and its prior metabolites along the pathway. This accumulation then initiates all those alternative glucose metabolic pathways such as the polyol pathway and the advanced glycation pathways that otherwise are minor and insignificant under euglycemic conditions. Importantly, all these alternative pathways lead to ROS production, thus aggravating cellular oxidative stress. Therefore, reductive stress followed by oxidative stress comprises a major mechanism of hyperglycemiainduced metabolic syndrome.
\end{abstract}

\section{Introduction}

Type 2 diabetes is generally an overnutritional disease [13]. It is caused by insulin resistance and insulin secretion impairment induced gradually and mainly by high blood glucose in conjunction with other factors such as obesity, aging, genetic predisposition, and physical inactivity [4-9]. Persistent overnutrition creates a steady level of high blood glucose that is toxic to macrovascular and microvascular systems [10-12], an effect known as glucotoxicity [13-17]. While oxidative stress is thought to contribute to the pathogenesis of glucotoxicity during the development of diabetes and diabetic complications [18-26], reductive stress due to excess NADH [27-33] generated by high blood glucose has attracted less attention. In this review, by following the mechanisms of NADH production and recycling, I highlight evidence that reductive stress followed by oxidative stress comprises the fundamental pathogenic mechanisms of chronic hyperglycemia in the development of diabetes and diabetic complications.

\section{Euglycemia}

A normal level of blood glucose below $100 \mathrm{mg} / \mathrm{dL}$ is tightly maintained, regulated, and achieved by rate of glucose uptake by all tissues and rate of glucose synthesis by the liver [34] and to a less magnitude by the kidney [35]. Approximately, $75 \%$ of the body's total glucose is consumed by insulininsensitive tissues including the brain, red blood cells, the liver, and the gut, while the rest is consumed by insulinsensitive tissues including muscle [36]. Postprandially, a rapid increase in blood glucose content stimulates insulin secretion, resulting in a temporary increase in blood insulin concentration known as hyperinsulinemia. The increases in blood concentrations of both glucose and insulin coordinately inhibit glucose production by the liver and facilitate glucose uptake by insulin-insensitive tissues [37]. Therefore, euglycemia is strictly maintained, which is highly dependent not only on proper insulin secretion from the $\beta$-cells upon nutritional stimulation but also on insulin action in the liver and peripheral tissues [37]. 


\section{NADH and Reductive Stress}

Electrons from aerobic breakdown of glucose are mainly stored in NADH for oxygen reduction and ATP production. Therefore, NADH is a reducing compound and an excessive amount of it can cause reductive stress [30, 32, 38-40]. Overproduction of NADH or lack of $\mathrm{NAD}^{+}$can induce the accumulation of NADH, leading to imbalance between $\mathrm{NADH}$ and $\mathrm{NAD}^{+}$and creating a condition known as pseudohypoxia $[29,41-44]$. This is a condition under which oxygen cannot be effectively consumed. This would cause metabolic stress or metabolic syndrome as it often occurs in diabetes [44-47]. It should be noted that GSH and NADPH accumulation, tightly linked to NADH metabolism [48], can also induce reductive stress [39, 49-54]. As mitochondrial complex I is the major enzyme responsible for $\mathrm{NADH}$ recycling, impairment of complex I function can thus induce $\mathrm{NADH}$ accumulation and reductive stress [55] that could be linked to inhibition of insulin release by $\beta$-cells $[56,57]$.

\section{Hyperglycemia, Elevated Levels of NADH, and Mitochondrial Electron Pressure}

The glycolytic pathway breaks down nearly $80 \%-90 \%$ of the body's glucose, while the pentose phosphate pathway consumes the remaining $10 \%-20 \%$ under physiological condition $[58,59]$. Under hyperglycemic condition, more glucose will flux through the glycolytic pathway that produces more pyruvate and acetyl-CoA, leading to more NADH production. As NADH is an electron carrier, excess amount of it will cause an electron pressure on the mitochondrial electron transport chain $[40,60-62]$. This is particularly true for hepatocytes and pancreatic $\beta$-cells in that glucokinase (hexokinase D) is a supply-driven enzyme [63], and this enzyme is not inhibited by glucose-6-phosphate (G6P) [64$66]$. Therefore, the more glucose the more G6P produced that will be broken down through glycolysis and Krebs cycle, leading to more NADH production. Figure 1 shows the major conventional pathways that can generate more $\mathrm{NADH}$ when glucokinase is used to phosphorylate glucose for glucose breakdown in tissues such as pancreas and liver [67-70].

\section{NADH-Imposed Electron Pressure and Mitochondrial Superoxide Production}

The electron pressure induced by overproduced NADH will place a heavy burden on mitochondrial complex I that is the major site for NADH recycling (Figure 2). Under this condition, complex I will respond within its capacity to oxidize more $\mathrm{NADH}$ to $\mathrm{NAD}^{+}$, in an attempt to ameliorate the pseudohypoxic condition. An inherent nature of NADH flux through complex I is that more superoxide will also be made when more NADH is oxidized by complex I as this complex is also involved in proton pumping [71-73], leading to a proportional increase in electron leakage that will partially reduce oxygen to yield superoxide [71, 74-77]. This scenario could get worse under pseudohypoxic conditions as less $\mathrm{NAD}^{+}$is available for transporting electrons to oxygen
[55], leaving more oxygen available for partial reduction by the leaked electrons from complex I and complex III, the latter being also involved in proton pumping [78-80]. It should be noted that complex II and dihydrolipoamide dehydrogenase could also produce superoxide [81-83].

\section{Superoxide and Oxidative Stress}

Superoxide is the precursor of all reactive oxygen species that at elevated levels can cause oxidative stress [84, 85]. As has been established, superoxide can be converted to hydrogen peroxide by superoxide dismutase; hydrogen peroxide can then be converted to form hydroxyl radical by metal ions $[84,86,87]$. In the meantime, superoxide can also react with nitric oxide to produce peroxynitrite $\left(\mathrm{ONOO}^{-}\right)[88,89]$. All these reactive species can cause oxidation of proteins, lipids, and DNA [90]. Consequently, an oxidative stress condition has fully developed due to a high level of NADH, achieving the transition from reductive stress to oxidative stress [43, 9193]. Therefore, reductive stress is not the reverse of oxidative stress; it actually leads to oxidative stress $[94,95]$.

\section{Inhibition of Glyceraldehyde 3-Phosphate Dehydrogenase and Alternative Glucose Metabolic Pathways}

As has been discussed above, an oversupply of NADH can lead to overproduction of mitochondrial superoxide and other forms of ROS. These ROS can then impair the activity of glyceraldehyde 3-phosphate dehydrogenase (GAPDH) [22, 96] that is very sensitive to oxidative modifications [21, 97103] due to a redox-sensitive cysteine residue at its active center $[104,105]$. Additionally, high level of NADH would also inhibit GAPDH activity [106]. Such impairments would collectively decrease the efficiency of glucose metabolism via glycolysis and Krebs cycle, inducing accumulation of glyceraldehyde 3-phosphate (G3P). Therefore, all the intermediate products above and including G3P will have to be disposed by pathways that branch off the glycolytic pathways (Figure 3 ) $[107,108]$.

\section{The Branching-Off Pathways and Oxidative Stress}

There have been five pathways [21] that can branch off the glycolytic pathway under chronic hyperglycemic conditions (Figure 3). These pathways are minor and insignificant in glucose metabolism under normoglycemic conditions, but can become major pathways to flux high level glucose. As will be discussed below, all the five pathways have been linked to ROS production, oxidative stress, and the pathogenesis of diabetes and diabetic complications [21, 109-115].

8.1. The Polyol Pathway. When blood glucose level is high, cellular metabolic pathways change, which usually leads to deleterious effects [5]. A major pathway that is activated in response to hyperglycemia is the polyol pathway $[44,116-$ $118]$, in which glucose is reduced by aldose reductase to form 


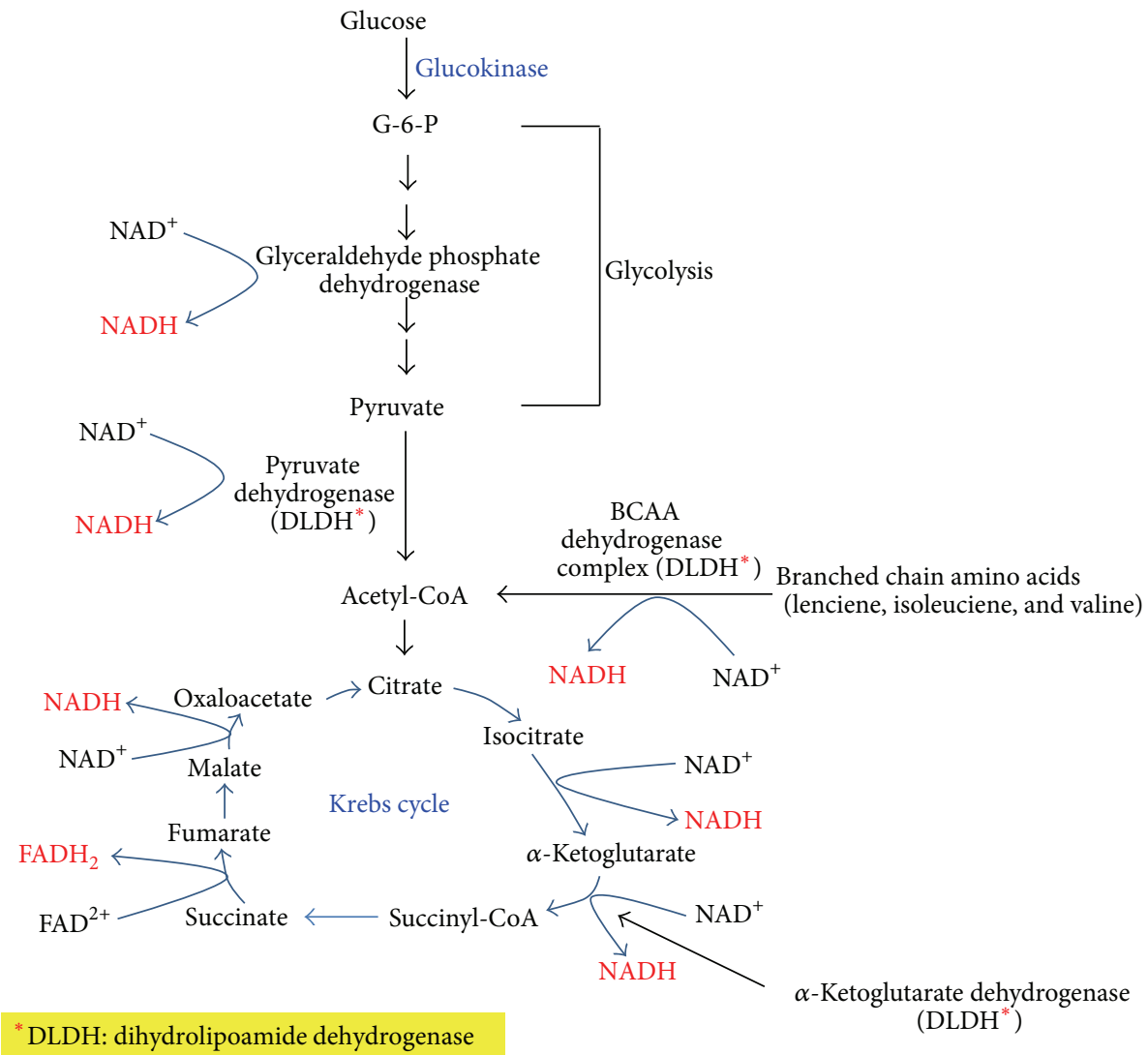

FIGURE 1: The conventional pathways that generate NADH by breaking down glucose via glycolysis and the Krebs cycle. The enzymes involved in NADH/NAD ${ }^{+}$recycling are shown. ${ }^{*} \mathrm{DLDH}$ stands for dihydrolipoamide dehydrogenase and is the component in each given enzyme complex that actually makes $\mathrm{NADH}$ from $\mathrm{NAD}^{+}[191]$.

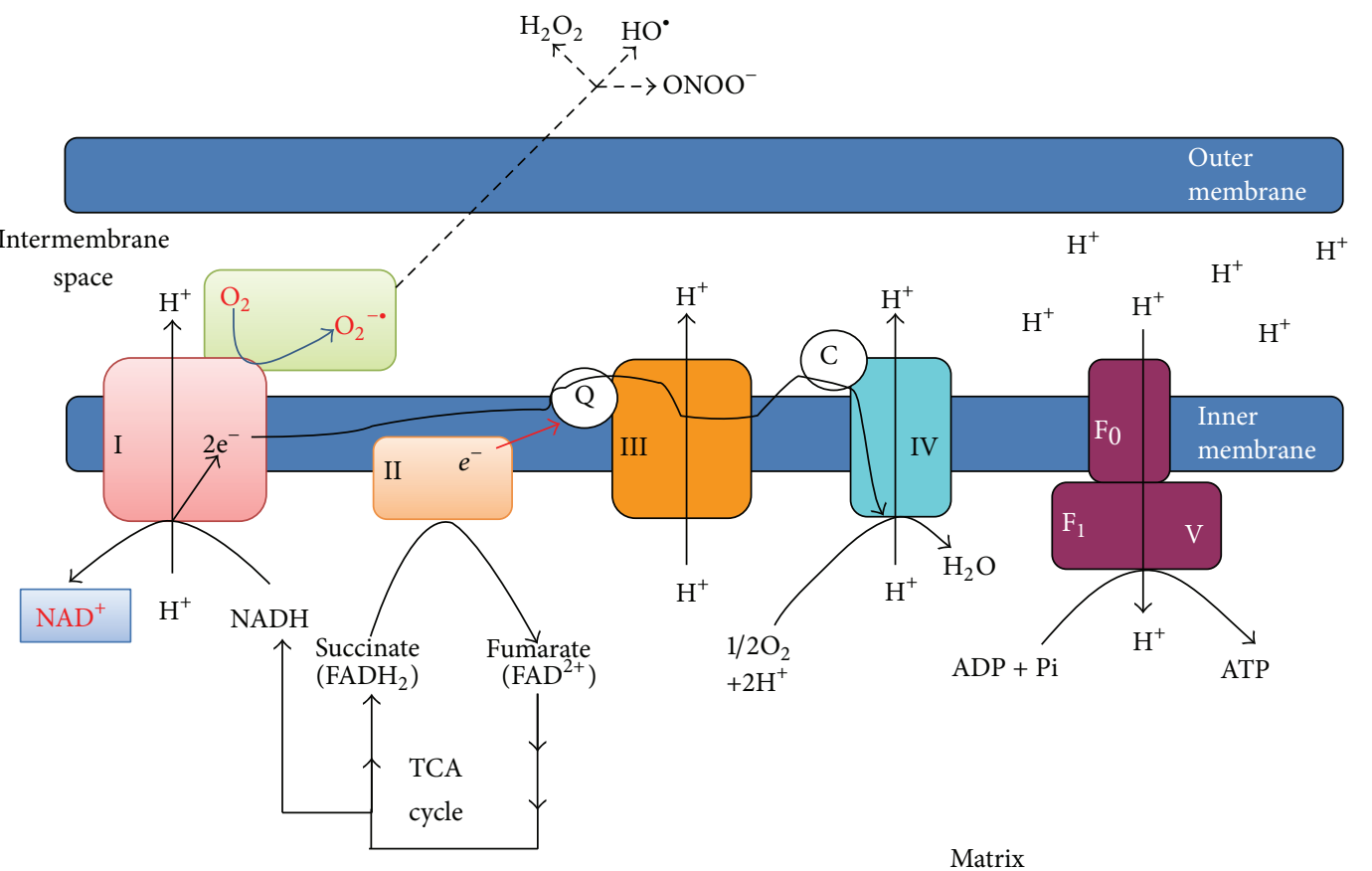

Figure 2: NADH oxidation by complex I in the electron transport chain. Electrons from NADH are transported via CoQ and cytochrome $\mathrm{c}$ to molecular oxygen. This process involves proton pumping that is tightly linked to superoxide production. ATP synthesis by complex $\mathrm{V}$ driven by the proton gradient is also shown. 


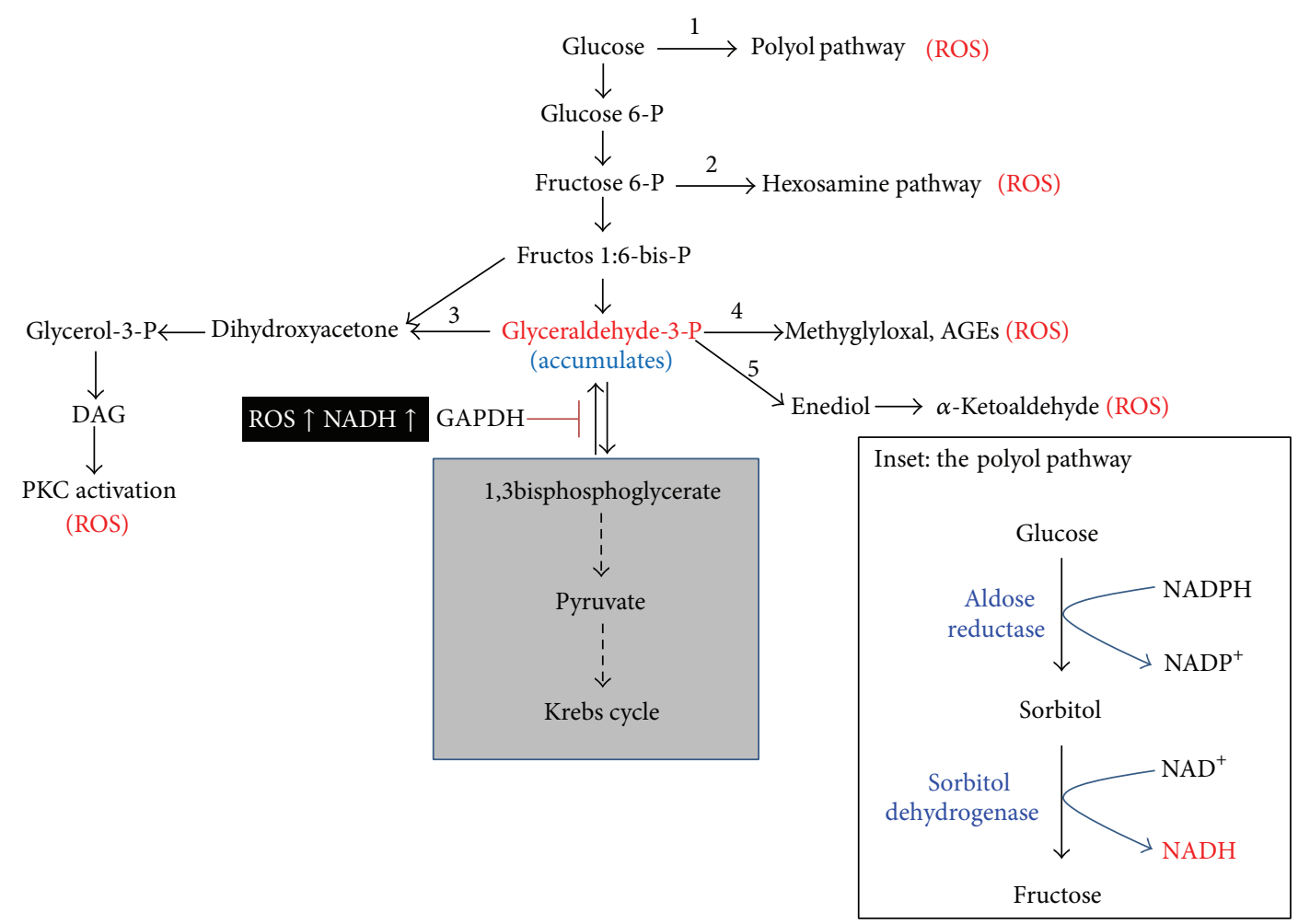

FIGURE 3: The branch-off pathways that are activated to dispose excess glucose when glyceraldehyde 3-phosphate dehydrogenase (GAPDH) is inactivated by ROS. These five alternative pathways [21, 115], in addition to the electron transport chain shown in Figure 2, are linked to ROS production, thus further exacerbating oxidative stress. Inset shows the polyol pathway. Pathways in the grey area would no longer efficiently break down glucose when GAPDH is inactivated by posttranslational modifications.

sorbitol, and the formed sorbitol is then converted to fructose by sorbitol dehydrogenase. This pathway, as shown in Figure 3 (Inset), converts NADPH to NADH using two step reactions and leads to redox imbalance between $\mathrm{NADH}$ and $\mathrm{NAD}^{+}$. As the ratio of $\mathrm{NAD}^{+} / \mathrm{NADH}$ decreases due to an increase in NADH content, reductive stress can ensue. Because aldose reductase has a very high $\mathrm{Km}$ for glucose [119], it can only be activated by a high level of glucose. Hence, this enzyme could also be considered as a supply-driven enzyme [120,121]. Under hyperglycemic conditions, the polyol pathway has been estimated to utilize more than $30 \%$ of the body's glucose [101]. Therefore, this pathway can also contribute significantly to reductive stress $[32,119]$ and has been thought to play an important role in the pathogenesis of diabetic complications [122-125].

Additionally, in the first reaction of the polyol pathway (Figure 3 inset), NADPH is consumed and, when NADPH level goes lower, so does reduced form of glutathione (GSH). This is because glutathione reductase needs NADPH to regenerate GSH from GSSG (oxidized form of glutathione) [126]. As GSH level goes lower, cellular antioxidant capacity can be compromised, resulting in elevated levels of reactive oxygen species that can attack macromolecules and induce oxidative damage [126]. Therefore, the polyol pathway is also a source of oxidative stress [127-129]. It should also be pointed out that activation of the polyol pathway in return will further decrease glucose consumption by the glycolytic pathway as sorbitol dehydrogenase competes with GAPDH for $\mathrm{NAD}^{+}[130,131]$. Moreover, as nitric oxide synthase also uses NADPH as a cofactor, a lowered level of NADPH can lead to a decrease in nitric oxide production, thereby facilitating vasoconstriction and platelet aggregation [132].

8.2. The Hexosamine Pathway. This pathway branches off from fructose 6-phosphate in the glycolytic pathway. Fructose 6-phosphate is the substrate of the enzyme glutaminefructose 6-P amidotransferase (GFAT), which is the ratelimiting enzyme for this pathway. GFAT makes glucosamine 6-P from fructose 6-P and the former is further converted to UDP-N-acetylglucosamine, which is the substrate for specific O-GlcNAc transferase that catalyzes posttranslational modifications of proteins via O-GlcNAc on serine and threonine residues [133-135]. Increased glucose flux through this pathway has been shown to be involved in ROS generation and oxidative stress [136-138] and has been implicated in diabetic complications [139-142].

8.3. The Protein Kinase C Activation Pathway. Fructose 1:6bisphosphate can break down to form dihydroxyacetone phosphate and glyceraldehyde 3-phosphate with the former being readily isomerized to glyceraldehyde 3-phosphate under the action of triose phosphate isomerase. Accumulation of glyceraldehyde 3-phosphate can increase the synthesis of diacylglycerol that is an activator of protein kinase $\mathrm{C}$ 
(PKC). PKC activation is known to be involved in elevating the content of TGF- $\beta-1$, endothelin-1, NF- $\kappa$ B, and vascular endothelial growth factor $[22,143,144]$ and is also known to induce ROS production by NADPH oxidase that catalyzes one electron reduction of molecular oxygen to form superoxide [145-147]. Mechanistically, it has been established that PKC activates NADPH oxidase by phosphorylating the $\mathrm{p} 47^{\text {phox }}$ subunit, triggering the translocation of this subunit from cytosol to membrane whereby it assembles with other components to form an active NADPH oxidase that is capable of making superoxide from oxygen [148, 149]. PKC activation can also induce insulin resistance by inhibiting Akt-dependent nitric oxide synthase function [150].

8.4. Advanced Glycation End Products (AGEs). In addition to the polyol pathway, this pathway has also been thought to be a major mechanism of oxidative stress under hyperglycemic condition [151, 152]. High level of glucose can induce formation of methylglyoxal from glyceraldehyde 3-phosphate when GAPDH function is impaired. Methylglyoxal can modify proteins via glycation of amino groups on proteins $[153,154]$. One of the major products is glycated hemoglobin (HbAlc) that has been used as a biomarker for diabetes $[155,156]$. Therefore, this nonenzymatic process can greatly impair protein function. Moreover, this glycation pathway is known to liberate ROS $[157,158]$ and upregulate the expression of cell surface receptor for AGEs, leading to activation of the NF- $\kappa \mathrm{B}$ signaling pathway and chronic inflammation [159-161].

8.5. The Glyceraldehyde Autoxidation Pathway. This pathway also branches off from glyceraldehyde 3-phosphate in the glycolytic pathway. Glyceraldehyde 3-phosphate is formed from fructose 1:6-bisphospate by the enzyme aldose. Under certain conditions, glyceraldehyde 3-phosphate can undergo autoxidation [162], a process that can generate hydrogen peroxide and $\alpha$-ketoaldehydes in diabetes mellitus $[21,163]$.

\section{Oxidative Stress, Diabetes, and Diabetic Complications}

As discussed above, all the sources of ROS and oxidative stress can be traced back to high blood glucose and $\mathrm{NADH}$ overproduction. Therefore, chronic hyperglycemia would inevitably cause chronic reductive stress that leads to oxidative stress. As ROS production is a common feature of the above described pathways $[119,164]$, chronic oxidative stress certainly plays a central role in the development of diabetes and diabetic complications [22, 165, 166]. Indeed, it has been reported that ROS can induce insulin resistance [74, 167], impair insulin synthesis [168], and impair beta cell insulin secretion $[97,169]$. Additionally, oxidative stress biomarkers have been shown to be increased in individuals who exhibit insulin resistance [170-173] or insulin secretion impairment [174-177], indicating a positive correlation between oxidative stress and insulin resistance and insulin secretion impairment. Moreover, numerous studies have also established that ROS are involved in the etiology of diabetic

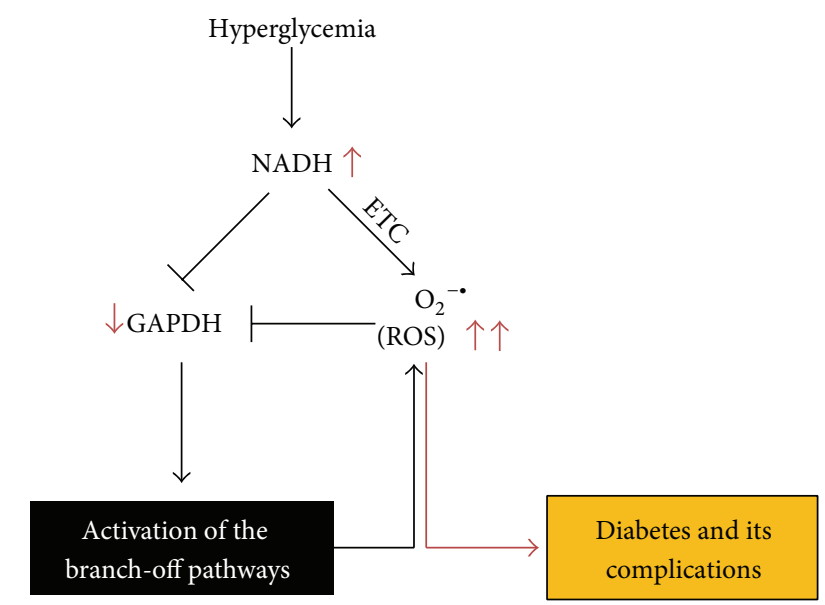

FIgURE 4: Hyperglycemia induces overproduction of NADH and mitochondrial ROS that inhibit GAPDH activity. This inhibition then activates the alternative glucose metabolic pathways, which further produce ROS involved in glucotoxicity that is responsible for the development of diabetes and diabetic complications. ETC: electron transport chain.

complications including retinopathy, neuropathy, cardiomyopathy, and nephropathy [123, 178-182]. Given that oxidative stress originates from $\mathrm{NADH}$-imposed reductive stress [31, 183], attenuating hyperglycemia-triggered reductive stress may provide potential therapeutic approaches for preventing the development of diabetes and diabetic complications.

\section{Conclusion}

Persistent high blood glucose is highly toxic $[16,112]$. It not only induces insulin resistance but also impairs insulin secretion by pancreatic $\beta$-cells [184]. Over time, hyperglycemia will produce detrimental effects on macrovascular and microvascular systems $[185,186]$. Figure 4 summarizes schematically the pathways discussed in this review and their pathogenic roles in chronic hyperglycemia via $\mathrm{NADH}, \mathrm{ROS}$, and oxidative stress. As hyperglycemia results in excessive production of acetyl-CoA that feeds into the Krebs cycle, making excess NADH, mitochondrial electron transport chain is thus under heavy electron pressure [40, $60,61]$. Therefore, oxidation of the overproduced NADH by mitochondria will inevitably lead to production of more superoxide and hence more ROS $[187,188]$, which can in turn attack and inactivate GAPDH. This would trigger the accumulation of glycolytic metabolites upstream of glyceraldehyde 3-phosphate and activate the alternative glucose disposal pathways that all are linked to ROS production and hence increase the magnitude of oxidative stress $[21,189,190]$. Therefore, reductive stress followed by oxidative stress could serve as the major mechanism of glucotoxicity under chronic hyperglycemic conditions. An increase in NADH oxidation by mitochondria without an accompanying increase in ROS production may be a potential therapeutic approach for diabetes and diabetic complications. 


\section{Conflict of Interests}

The author declares that there is no conflict of interests regarding the publication of this paper.

\section{Acknowledgment}

Liang-Jun Yan is supported in part by a Grant from the National Institute of Neurological Disorders and Stroke (R01NS079792).

\section{References}

[1] M. Prentki and C. J. Nolan, "Islet $\beta$ cell failure in type 2 diabetes," Journal of Clinical Investigation, vol. 116, no. 7, pp. 1802-1812, 2006.

[2] D. Gupta, C. B. Krueger, and G. Lastra, "Over-nutrition, obesity and insulin resistance in the development of $\beta$-cell dysfunction," Current Diabetes Reviews, vol. 8, no. 2, pp. 76-83, 2012.

[3] D. Cai, "Neuroinflammation and neurodegeneration in overnutrition-induced diseases," Trends in Endocrinology and Metabolism, vol. 24, no. 1, pp. 40-47, 2013.

[4] R. A. DeFronzo, "Insulin resistance: a multifaceted syndrome responsible for NIDDM, obesity, hypertension, dyslipidaemia and atherosclerosis," Netherlands Journal of Medicine, vol. 50, no. 5, pp. 191-197, 1997.

[5] B. Tuch, M. Dunlop, and J. Proietto, Diabetes Research: A Guide for Postgraduates, Harwood Academic Publishers, 2000.

[6] A. H. Barnett, Type 2 Diabetes, Oxford University Press, 2nd edition, 2012.

[7] R. A. DeFronzo, "Pathogenesis of type 2 diabetes mellitus," Medical Clinics of North America, vol. 88, no. 4, pp. 787-835, 2004.

[8] S. E. Kahn, M. E. Cooper, and S. Del Prato, "Pathophysiology and treatment of type 2 diabetes: perspectives on the past, present, and future," The Lancet, vol. 383, pp. 1068-1083, 2014.

[9] T. Szkudelski, "Streptozotocin-nicotinamide-induced diabetes in the rat. Characteristics of the experimental model," Experimental Biology and Medicine, vol. 237, no. 5, pp. 481-490, 2012.

[10] A. M. Heagerty, C. Aalkjaer, S. J. Bund, N. Korsgaard, and M. J. Mulvany, "Small artery structure in hypertension: dual processes of remodeling and growth," Hypertension, vol. 21, no. 4, pp. 391-397, 1993.

[11] J. M. Forbes and M. E. Cooper, "Mechanisms of diabetic complications," Physiological Reviews, vol. 93, no. 1, pp. 137-188, 2013.

[12] A. Stirban, T. Gawlowski, and M. Roden, "Vascular effects of advanced glycation endproducts: clinical effects and molecular mechanisms," Molecular Metabolism, vol. 3, pp. 94-108, 2013.

[13] G. Leibowitz, E. Bachar, M. Shaked et al., "Glucose regulation of $\beta$-cell stress in type 2 diabetes," Diabetes, Obesity and Metabolism, vol. 12, no. 2, pp. 66-75, 2010.

[14] B. P. Somesh, M. K. Verma, M. K. Sadasivuni et al., "Chronic glucolipotoxic conditions in pancreatic islets impair insulin secretion due to dysregulated calcium dynamics, glucose responsiveness and mitochondrial activity," BMC Cell Biology, vol. 14, no. 1, article 31, 2013.

[15] G. V. Z. Dedoussis, A. C. Kaliora, and D. B. Panagiotakos, "Genes, diet and type 2 diabetes mellitus: a review," Review of Diabetic Studies, vol. 4, no. 1, pp. 13-24, 2007.
[16] S. Del Prato, "Role of glucotoxicity and lipotoxicity in the pathophysiology of Type 2 diabetes mellitus and emerging treatment strategies," Diabetic Medicine, vol. 26, no. 12, pp. 11851192, 2009.

[17] M. Bensellam, D. R. Laybutt, and J.-C. Jonas, "The molecular mechanisms of pancreatic $\beta$-cell glucotoxicity: recent findings and future research directions," Molecular and Cellular Endocrinology, vol. 364, no. 1-2, pp. 1-27, 2012.

[18] P. Rösen, P. P. Nawroth, G. King, W. Möller, H.-J. Tritschler, and L. Packer, "The role of oxidative stress in the onset and progression of diabetes and its complications: a summary of a congress series sponsored by UNESCO-MCBN, the American diabetes association and the German diabetes society," Diabetes/Metabolism Research and Reviews, vol. 17, no. 3, pp. 189212, 2001

[19] S. D. M. Bandeira, L. J. S. da Fonseca, G. D. S. Guedes, L. A. Rabelo, M. O. F. Goulart, and S. M. L. Vasconcelos, "Oxidative stress as an underlying contributor in the development of chronic complications in diabetes mellitus," International Journal of Molecular Sciences, vol. 14, no. 2, pp. 3265-3284, 2013.

[20] K. Stadler, "Oxidative stress in diabetes," Advances in Experimental Medicine and Biology, vol. 771, pp. 272-287, 2012.

[21] A. P. Robertson, "Chronic oxidative stress as a central mechanism for glucose toxicity in pancreatic islet beta cells in diabetes," Journal of Biological Chemistry, vol. 279, no. 41, pp. 42351-42354, 2004.

[22] F. Giacco and M. Brownlee, "Oxidative stress and diabetic complications," Circulation Research, vol. 107, no. 9, pp. 10581070, 2010.

[23] M. K. Arora and U. K. Singh, "Oxidative stress: meeting multiple targets in pathogenesis of diabetic nephropathy," Current Drug Targets, vol. 15, pp. 531-538, 2014.

[24] T. V. Fiorentino, A. Prioletta, P. Zuo, and F. Folli, "Hyperglycemia-induced oxidative stress and its role in diabetes mellitus related cardiovascular diseases," Current Pharmaceutical Design, vol. 19, pp. 5695-5703, 2013.

[25] R. Mortuza and S. Chakrabarti, "Glucose-induced cell signaling in the pathogenesis of diabetic cardiomyopathy," Heart Failure Reviews, vol. 19, no. 1, pp. 75-86, 2014.

[26] N. B. Ruderman, D. Carling, M. Prentki, and J. M. Cacicedo, "AMPK, insulin resistance, and the metabolic syndrome," Journal of Clinical Investigation, vol. 123, no. 7, pp. 2764-2772, 2013.

[27] J. R. Williamson and Y. Ido, "Understanding retinal cytosolic reductive stress," Investigative Ophthalmology \& Visual Science, vol. 39, no. 7, pp. 1295-1296, 1998.

[28] J. R. Williamson, C. Kilo, and Y. Ido, “The role of cytosolic reductive stress in oxidant formation and diabetic complications," Diabetes Research and Clinical Practice, vol. 45, no. 2-3, pp. 81-82, 1999.

[29] Y. Ido and J. R. Williamson, "Hyperglycemic cytosolic reductive stress "pseudohypoxia": implications for diabetic retinopathy," Investigative Ophthalmology \& Visual Science, vol. 38, no. 8, pp. 1467-1470, 1997.

[30] M. Ghyczy and M. Boros, "Electrophilic methyl groups present in the diet ameliorate pathological states induced by reductive and oxidative stress: a hypothesis," British Journal of Nutrition, vol. 85, no. 4, pp. 409-414, 2001.

[31] J. S. Teodoro, A. P. Rolo, and C. M. Palmeira, "The NAD ratio redox paradox: why does too much reductive power cause oxidative stress?" Toxicology Mechanisms and Methods, vol. 23, no. 5, pp. 297-302, 2013. 
[32] R. G. Tilton, "Diabetic vascular dysfunction: links to glucoseinduced reductive stress and VEGF," Microscopy Research and Technique, vol. 57, no. 5, pp. 390-407, 2002.

[33] R. Bassi, A. Trevisani, S. Tezza et al., "Regenerative therapies for diabetic microangiopathy," Experimental Diabetes Research, vol. 2012, Article ID 916560, 11 pages, 2012.

[34] P. J. Klover and R. A. Mooney, "Hepatocytes: critical for glucose homeostasis," International Journal of Biochemistry and Cell Biology, vol. 36, no. 5, pp. 753-758, 2004.

[35] J. E. Gerich, H. J. Woerle, C. Meyer, and M. Stumvoll, "Renal gluconeogenesis: its importance in human glucose homeostasis," Diabetes Care, vol. 24, no. 2, pp. 382-391, 2001.

[36] J. E. Gerich, "Control of glycaemia," Bailliere's Clinical Endocrinology and Metabolism, vol. 7, no. 3, pp. 551-586, 1993.

[37] R. A. DeFronzo and E. Ferrannini, "Regulation of hepatic glucose metabolism in humans," Diabetes/Metabolism Reviews, vol. 3, no. 2, pp. 415-459, 1987.

[38] H. Valadi, A. Valadi, R. Ansell et al., "NADH-reductive stress in Saccharomyces cerevisiae induces the expression of the minor isoform of glyceraldehyde-3-phosphate dehydrogenase (TDH1)," Current Genetics, vol. 45, no. 2, pp. 90-95, 2004.

[39] A. Farhana, L. Guidry, A. Srivastava, A. Singh, M. K. Hondalus, and A. J. C. Steyn, "Reductive stress in microbes: implications for understanding mycobacterium tuberculosis disease and persistence," Advances in Microbial Physiology, vol. 57, pp. 43117, 2010.

[40] B. Lipinski, M. Ghyczy, and M. Boros, "Evidence in support of a concept of reductive stress (multiple letters)," British Journal of Nutrition, vol. 87, no. 1, pp. 93-94, 2002.

[41] A. P. Gomes, N. L. Price, A. J. Ling et al., "Declining $\mathrm{NAD}(+)$ induces a pseudohypoxic state disrupting nuclearmitochondrial communication during aging," Cell, vol. 155, pp. 1624-1638, 2013.

[42] I. G. Obrosova, M. J. Stevens, and H.-J. Lang, "Diabetes-induced changes in retinal NAD-redox status: pharmacological modulation and implications for pathogenesis of diabetic retinopathy," Pharmacology, vol. 62, no. 3, pp. 172-180, 2001.

[43] M. K. Van den Enden, J. R. Nyengaard, E. Ostrow, J. H. Burgan, and J. R. Williamson, "Elevated glucose levels increase retinal glycolysis and sorbitol pathway metabolism: implications for diabetic retinopathy," Investigative Ophthalmology and Visual Science, vol. 36, no. 8, pp. 1675-1685, 1995.

[44] J. R. Williamson, K. Chang, M. Frangos et al., "Hyperglycemic pseudohypoxia and diabetic complications," Diabetes, vol. 42, no. 6, pp. 801-813, 1993.

[45] E. H. Karunanayake, D. J. Hearse, and G. Mellows, "The synthesis of [14C]streptozotocin and its distribution and excretion in the rat," Biochemical Journal, vol. 142, no. 3, pp. 673-683, 1974.

[46] L. Virág and C. Szabó, “The therapeutic potential of poly(ADPribose) polymerase inhibitors," Pharmacological Reviews, vol. 54, no. 3, pp. 375-429, 2002.

[47] J. Chiu, B. Y. Xu, S. Chen, B. Feng, and S. Chakrabarti, "Oxidative stress-induced, poly(ADP-ribose) polymerase-dependent upregulation of ET-1 expression in chronic diabetic complications," Canadian Journal of Physiology and Pharmacology, vol. 86, no. 6, pp. 365-372, 2008.

[48] S.-I. Oka, C.-P. Hsu, and J. Sadoshima, "Regulation of cell survival and death by pyridine nucleotides," Circulation Research, vol. 111, no. 5, pp. 611-627, 2012.

[49] G. Bánhegyi, J. Mandl, and M. Csala, "Redox-based endoplasmic reticulum dysfunction in neurological diseases," Journal of Neurochemistry, vol. 107, no. 1, pp. 20-34, 2008.
[50] N. S. Rajasekaran, P. Connell, E. S. Christians et al., "Human $\alpha$ Bcrystallin mutation causes oxido-reductive stress and protein aggregation cardiomyopathy in mice," Cell, vol. 130, no. 3, pp. 427-439, 2007.

[51] Q. Yu, C. F. Lee, W. Wang et al., "Elimination of NADPH oxidase activity promotes reductive stress and sensitizes the heart to ischemic injury," Journal of the American Heart Association, vol. 3, Article ID e000555, 2014.

[52] D. P. Jones and Y.-M. Go, "Redox compartmentalization and cellular stress," Diabetes, Obesity and Metabolism, vol. 12, no. 2, pp. 116-125, 2010.

[53] J. Lugrin, N. Rosenblatt-Velin, R. Parapanov, and L. Liaudet, "The role of oxidative stress during inflammatory processes," Biological Chemistry, vol. 395, pp. 203-230, 2014.

[54] R. K. Naviaux, “Oxidative shielding or oxidative stress?” Journal of Pharmacology and Experimental Therapeutics, vol. 342, no. 3, pp. 608-618, 2012.

[55] Q. He, M. Wang, C. Petucci, S. J. Gardell, and X. Han, "Rotenone induces reductive stress and triacylglycerol deposition in $\mathrm{C} 2 \mathrm{C} 12$ cells," International Journal of Biochemistry and Cell Biology, vol. 45, pp. 2749-2755, 2013.

[56] M. D. Esposti, A. Ngo, and M. A. Myers, "Inhibition of mitochondrial complex I may account for IDDM induced by intoxication with the rodenticide vacor," Diabetes, vol. 45 , no. 11, pp. 1531-1534, 1996.

[57] D. W. Lamson and S. M. Plaza, "Mitochondrial factors in the pathogenesis of diabetes: a hypothesis for treatment," Alternative Medicine Review, vol. 7, no. 2, pp. 94-111, 2002.

[58] M. A. Abdul-Ghani and R. A. DeFronzo, "Pathogenesis of insulin resistance in skeletal muscle," Journal of Biomedicine and Biotechnology, vol. 2010, Article ID 476279, 19 pages, 2010.

[59] M. M. C. Wamelink, E. A. Struys, and C. Jakobs, "The biochemistry, metabolism and inherited defects of the pentose phosphate pathway: a review," Journal of Inherited Metabolic Disease, vol. 31, no. 6, pp. 703-717, 2008.

[60] M. S. Ola, D. A. Berkich, Y. Xu et al., "Analysis of glucose metabolism in diabetic rat retinas," The American Journal of Physiology: Endocrinology and Metabolism, vol. 290, no. 6, pp. E1057-E1067, 2006.

[61] M. G. Rosca, E. J. Vazquez, Q. Chen, J. Kerner, T. S. Kern, and C. L. Hoppel, "Oxidation of fatty acids is the source of increased mitochondrial reactive oxygen species production in kidney cortical tubules in early diabetes," Diabetes, vol. 61, no. 8, pp. 2074-2083, 2012.

[62] O. R. Rebolledo and S. M. Actis Dato, "Postprandial hyperglycemia and hyperlipidemia-generated glycoxidative stress: its contribution to the pathogenesis of diabetes complications," European Review for Medical and Pharmacological Sciences, vol. 9, no. 4, pp. 191-208, 2005.

[63] A. Reyes and M. L. Cardenas, "All hexokinase isoenzymes coexist in rat hepatocytes," Biochemical Journal, vol. 221, no. 2, pp. 303-309, 1984.

[64] P. J. Otaegui, T. Ferre, A. Pujol, E. Riu, R. Jimenez, and F. Bosch, "Expression of glucokinase in skeletal muscle: a new approach to counteract diabetic hyperglycemia," Human Gene Therapy, vol. 11, no. 11, pp. 1543-1552, 2000.

[65] M. Pal, "Recent advances in glucokinase activators for the treatment of type 2 diabetes," Drug Discovery Today, vol. 14, no. 15-16, pp. 784-792, 2009.

[66] F. M. Matschinsky, "Regulation of pancreatic $\beta$-cell glucokinase: from basics to therapeutics," Diabetes, vol. 51, no. 3, pp. S394S404, 2002. 
[67] F. Matschinsky, Y. Liang, P. Kesavan et al., "Glucokinase as pancreatic $\beta$ cell glucose sensor and diabetes gene," Journal of Clinical Investigation, vol. 92, no. 5, pp. 2092-2098, 1993.

[68] C. Postic, M. Shiota, and M. A. Magnuson, "Cell-specific roles of glucokinase in glucose homeostasis," Recent Progress in Hormone Research, vol. 56, pp. 195-217, 2001.

[69] M. Larion and B. G. Miller, "Homotropic allosteric regulation in monomeric mammalian glucokinase," Archives of Biochemistry and Biophysics, vol. 519, no. 2, pp. 103-111, 2012.

[70] S. Lenzen, "A fresh view of glycolysis and glucokinase regulation: history and current status," Journal of Biological Chemistry, vol. 289, no. 18, pp. 12189-12194, 2014.

[71] J. Hirst, M. S. King, and K. R. Pryde, "The production of reactive oxygen species by complex I," Biochemical Society Transactions, vol. 36, no. 5, pp. 976-980, 2008.

[72] K. R. Pryde and J. Hirst, "Superoxide is produced by the reduced flavin in mitochondrial complex I: a single, unified mechanism that applies during both forward and reverse electron transfer," Journal of Biological Chemistry, vol. 286, no. 20, pp. 1805618065, 2011.

[73] J. Hirst, "Mitochondrial complex I," Annual Review of Biochemistry, vol. 82, pp. 551-575, 2013.

[74] J.-A. Kim, Y. Wei, and J. R. Sowers, "Role of mitochondrial dysfunction in insulin resistance," Circulation Research, vol. 102, no. 4, pp. 401-414, 2008.

[75] L. J. Yan, "Protein redox modification as a cellular defense mechanism against tissue ischemic injury," Oxidative Medicine and Cellular Longevity, vol. 2014, Article ID 343154, 12 pages, 2014.

[76] D. Esterházy, M. S. King, G. Yakovlev, and J. Hirst, "Production of reactive oxygen species by complex I (NADH:ubiquinone oxidoreductase) from Escherichia coli and comparison to the enzyme from mitochondria," Biochemistry, vol. 47, no. 12, pp. 3964-3971, 2008.

[77] A. Ceriello, "Postprandial hyperglycemia and diabetes complications: is it time to treat?" Diabetes, vol. 54, no. 1, pp. 1-7, 2005.

[78] J. St-Pierre, J. A. Buckingham, S. J. Roebuck, and M. D. Brand, "Topology of superoxide production from different sites in the mitochondrial electron transport chain," Journal of Biological Chemistry, vol. 277, no. 47, pp. 44784-44790, 2002.

[79] M. P. Murphy, "How mitochondria produce reactive oxygen species," Biochemical Journal, vol. 417, no. 1, pp. 1-13, 2009.

[80] S. Dröse and U. Brandt, "Molecular mechanisms of superoxide production by the mitochondrial respiratory chain," Advances in Experimental Medicine and Biology, vol. 748, pp. 145-169, 2012.

[81] I. Siebels and S. Drose, "Q-site inhibitor induced ROS production of mitochondrial complex II is attenuated by TCA cycle dicarboxylates," Biochimica et Biophysica Acta, vol. 1827, pp. 1156-1164, 2013.

[82] L.-J. Yan, N. Sumien, N. Thangthaeng, and M. J. Forster, "Reversible inactivation of dihydrolipoamide dehydrogenase by mitochondrial hydrogen peroxide," Free Radical Research, vol. 47, no. 2, pp. 123-133, 2013.

[83] C. L. Quinlan, R. L. Goncalves, M. Hey-Mogensen, N. Yadava, V. I. Bunik, and M. D. Brand, "The 2-oxoacid dehydrogenase complexes in mitochondria can produce superoxide/hydrogen peroxide at much higher rates than complex I," Journal of Biological Chemistry, 2014.

[84] M. J. Jackson, S. Papa, J. Bolaños et al., "Antioxidants, reactive oxygen and nitrogen species, gene induction and mitochondrial function," Molecular Aspects of Medicine, vol. 23, no. 1-3, pp. 209-285, 2002.

[85] L. J. Yan, "Positive oxidative stress in aging and aging-related disease tolerance," Redox Biology, vol. 2, pp. 165-169, 2014.

[86] J. F. Turrens, A. Alexandre, and A. L. Lehninger, "Ubisemiquinone is the electron donor for superoxide formation by complex III of heart mitochondria," Archives of Biochemistry and Biophysics, vol. 237, no. 2, pp. 408-414, 1985.

[87] J. F. Turrens, "Superoxide production by the mitochondrial respiratory chain," Bioscience Reports, vol. 17, no. 1, pp. 3-8, 1997.

[88] Z. Cai and L. J. Yan, "Protein oxidative modifications: beneficial roles in disease and health," Journal of Biochemical and Pharmacological Research, vol. 1, pp. 15-26, 2013.

[89] S. Shah, M. Iqbal, J. Karam, M. Salifu, and S. I. McFarlane, "Oxidative stress, glucose metabolism, and the prevention of type 2 diabetes: pathophysiological insights," Antioxidants and Redox Signaling, vol. 9, no. 7, pp. 911-929, 2007.

[90] L. J. Yan, "Analysis of oxidative modification of proteins," in Current Protocols in Protein Science, chapter 14, unit 14, 2009.

[91] E. R. Stadtman, “Biochemical markers of aging," Experimental Gerontology, vol. 23, no. 4-5, pp. 327-347, 1988.

[92] L.-J. Yan, R. L. Levine, and R. S. Sohal, "Oxidative damage during aging targets mitochondrial aconitase," Proceedings of the National Academy of Sciences of the United States of America, vol. 94, pp. 11168-11172, 1997.

[93] T. L. Dawson, G. J. Gores, A.-L. Nieminen, B. Herman, and J. J. Lemasters, "Mitochondria as a source of reactive oxygen species during reductive stress in rat hepatocytes," The American Journal of Physiology: Cell Physiology, vol. 264, no. 4, pp. C961C967, 1993.

[94] Y. F. Pung and W. M. Chilian, "Corruption of coronary collateral growth in metabolic syndrome: role of oxidative stress," World Journal of Cardiology, vol. 2, pp. 421-427, 2010.

[95] M. L. Pall, Explaining “Unexplained Illnesses": Disease Paradigm for Chronic Fatigue Syndrome, Multiple Chemical Sensitivity, Fibromyalgia, Post-Traumatic Stress Disorder, and Gulf War Syndrome, Harrington Park Press, 2007.

[96] M. Brownlee, "Biochemistry and molecular cell biology of diabetic complications," Nature, vol. 414, no. 6865, pp. 813-820, 2001.

[97] K. Sakai, K. Matsumoto, T. Nishikawa et al., "Mitochondrial reactive oxygen species reduce insulin secretion by pancreatic $\beta$-cells," Biochemical and Biophysical Research Communications, vol. 300, no. 1, pp. 216-222, 2003.

[98] X. Du, T. Matsumura, D. Edelstein et al., "Inhibition of GAPDH activity by poly(ADP-ribose) polymerase activates three major pathways of hyperglycemic damage in endothelial cells," Journal of Clinical Investigation, vol. 112, no. 7, pp. 1049-1057, 2003.

[99] T. Zhang, Y. Gong, H. Zhou, P. Xie, S. Guan, and W. Yi, "Oxidative stress-the key mechanisms of diabetic peripheral neuropathy," North The American Journal of Medicine and Science, vol. 6, pp. 87-90, 2013.

[100] S. Madsen-Bouterse, G. Mohammad, and R. A. Kowluru, "Glyceraldehyde-3-phosphate dehydrogenase in retinal microvasculature: implications for the development and progression of diabetic retinopathy," Investigative Ophthalmology and Visual Science, vol. 51, no. 3, pp. 1765-1772, 2010.

[101] I. G. Fantus, "The pathogenesis of the chronic complications of the diabetes mellitus," Endocrinology Rounds, vol. 2, pp. 1-8, 2002. 
[102] P. Puthanveetil, D. Zhang, Y. Wang et al., "Diabetes triggers a PARP1 mediated death pathway in the heart through participation of FoxO1," Journal of Molecular and Cellular Cardiology, vol. 53, no. 5, pp. 677-686, 2012.

[103] N. R. Hwang, S.-H. Yim, Y. M. Kim et al., "Oxidative modifications of glyceraldehyde-3-phosphate dehydrogenase play a key role in its multiple cellular functions," Biochemical Journal, vol. 423, no. 2, pp. 253-264, 2009.

[104] D. R. Trentham, "Aspects of the chemistry of D-glyceraldehyde 3-phosphate dehydrogenase," Biochemical Journal, vol. 109, no. 4, pp. 603-612, 1968.

[105] J. Rivera-Nieves, W. C. Thompson, R. L. Levine, and J. Moss, "Thiols mediate superoxide-dependent NADH modification of glyceraldehyde-3-phosphate dehydrogenase," Journal of Biological Chemistry, vol. 274, no. 28, pp. 19525-19531, 1999.

[106] J. R. Ussher, J. S. Jaswal, and G. D. Lopaschuk, "Pyridine nucleotide regulation of cardiac intermediary metabolism," Circulation Research, vol. 111, no. 5, pp. 628-641, 2012.

[107] S. D. Funk, A. Yurdagul, and A. W. Orr, "Hyperglycemia and endothelial dysfunction in atherosclerosis: lessons from type 1 diabetes," International Journal of Vascular Medicine, vol. 2012, Article ID 569654, 19 pages, 2012.

[108] C. Rask-Madsen and G. L. King, "Vascular complications of diabetes: mechanisms of injury and protective factors," Cell Metabolism, vol. 17, no. 1, pp. 20-33, 2013.

[109] M. A. Abdul-Ghani and R. A. DeFronzo, "Oxidative stress in type 2 diabetes," in Oxidative Stress in Aging, S. Miwa, K. B. Beckman, and F. L. Muller, Eds., pp. 191-212, Humana Press, 2008.

[110] M. B. Davidson, G. Bate, and P. Kirkpatrick, "Fresh from the pipeline: exenatide," Nature Reviews Drug Discovery, vol. 4, no. 9, pp. 713-714, 2005.

[111] V. Poitout and R. P. Robertson, "Minireview: secondary $\beta$-cell failure in type 2 diabetes: a convergence of glucotoxicity and lipotoxicity," Endocrinology, vol. 143, no. 2, pp. 339-342, 2002.

[112] V. Poitout and R. P. Robertson, "Glucolipotoxicity: fuel excess and $\beta$-cell dysfunction," Endocrine Reviews, vol. 29, no. 3, pp. 351-366, 2008.

[113] Y. Yang, M. R. Hayden, S. Sowers, S. V. Bagree, and J. R. Sowers, "Retinal redox stress and remodeling in cardiometabolic syndrome and diabetes," Oxidative Medicine and Cellular Longevity, vol. 3, no. $6,2010$.

[114] M. J. Callaghan, D. J. Ceradini, and G. C. Gurtner, "Hyperglycemia-induced reactive oxygen species and impaired endothelial progenitor cell function," Antioxidants and Redox Signaling, vol. 7, no. 11-12, pp. 1476-1482, 2005.

[115] A. Kassab and A. Piwowar, "Cell oxidant stress delivery and cell dysfunction onset in type 2 diabetes," Biochimie, vol. 94, no. 9, pp. 1837-1848, 2012.

[116] K. Yasunari, M. Kohno, H. Kano, M. Minami, and J. Yoshikawa, "Aldose reductase inhibitor improves insulin-mediated glucose uptake and prevents migration of human coronary artery smooth muscle cells induced by high glucose," Hypertension, vol. 35, no. 5, pp. 1092-1098, 2000.

[117] T. F. Ng, F. K. Lee, Z. T. Song et al., "Effects of sorbitol dehydrogenase deficiency on nerve conduction in experimental diabetic mice," Diabetes, vol. 47, pp. 961-966, 1998.

[118] A. Y. W. Lee and S. S. M. Chung, "Contributions of polyol pathway to oxidative stress in diabetic cataract," The FASEB Journal, vol. 13, no. 1, pp. 23-30, 1999.
[119] M. Brownlee, "The pathobiology of diabetic complications: a unifying mechanism," Diabetes, vol. 54, no. 6, pp. 1615-1625, 2005.

[120] C. Yabe-Nishimura, "Aldose reductase in glucose toxicity: a potential target for the prevention of diabetic complications," Pharmacological Reviews, vol. 50, no. 1, pp. 21-33, 1998.

[121] M. Dunlop, "Aldose reductase and the role of the polyol pathway in diabetic nephropathy," Kidney International, Supplement, vol. 58, no. 77, pp. S3-S12, 2000.

[122] L. A. Sena and N. S. Chandel, "Physiological roles of mitochondrial reactive oxygen species," Molecular Cell, vol. 48, no. 2, pp. 158-166, 2012.

[123] Q. Li, Y. C. Hwang, R. Ananthakrishnan, P. J. Oates, D. Guberski, and R. Ravichandran, "Polyol pathway and modulation of ischemia-reperfusion injury in Type 2 diabetic BBZ rat hearts," Cardiovascular Diabetology, vol. 7, article 33, 2008.

[124] K. H. Gabbay, "The sorbitol pathway and the complications of diabetes," The New England Journal of Medicine, vol. 288, no. 16, pp. 831-836, 1973.

[125] P. F. Kador and J. H. Kinoshita, "Role of aldose reductase in the development of diabetes-associated complications," The American Journal of Medicine A, vol. 79, no. 5, pp. 8-12, 1985.

[126] L.-J. Yan, E. S. Christians, L. Liu, X. Xiao, R. S. Sohal, and I. J. Benjamin, "Mouse heat shock transcription factor 1 deficiency alters cardiac redox homeostasis and increases mitochondrial oxidative damage," The EMBO Journal, vol. 21, no. 19, pp. 51645172, 2002.

[127] C. Ohmura, H. Watada, K. Azuma et al., "Aldose reductase inhibitor, epalrestat, reduces lipid hydroperoxides in type 2 diabetes," Endocrine Journal, vol. 56, no. 1, pp. 149-156, 2009.

[128] C.-M. Yeung, A. C. Y. Lo, A. K. H. Cheung, S. S. M. Chung, D. Wong, and S. K. Chung, "More severe type 2 diabetes-associated ischemic stroke injury is alleviated in aldose reductase-deficient mice," Journal of Neuroscience Research, vol. 88, no. 9, pp. 20262034, 2010

[129] W. H. Tang, K. A. Martin, and J. Hwa, "Aldose reductase, oxidative stress, and diabetic mellitus," Frontiers in Pharmacology, vol. 3, article 87, 2012.

[130] W. H. Tang, S. Wu, T. M. Wong, S. K. Chung, and S. S. M. Chung, "Polyol pathway mediates iron-induced oxidative injury in ischemic-reperfused rat heart," Free Radical Biology and Medicine, vol. 45, no. 5, pp. 602-610, 2008.

[131] Y. C. Hwang, S. Bakr, C. A. Ellery, P. J. Oates, and R. Ramasamy, "Sorbitol dehydrogenase: a novel target for adjunctive protection of ischemic myocardium," The FASEB Journal, vol. 17, no. 15, pp. 2331-2333, 2003.

[132] N. E. Cameron and M. A. Cotter, “The relationship of vascular changes to metabolic factors in diabetes mellitus and their role in the development of peripheral nerve complications," Diabetes/Metabolism Reviews, vol. 10, no. 3, pp. 189-224, 1994.

[133] T. Issad, E. Masson, and P. Pagesy, "O-GlcNAc modification, insulin signaling and diabetic complications," Diabetes and Metabolism, vol. 36, no. 6, pp. 423-435, 2010.

[134] J. Ma and G. W. Hart, "Protein O-GlcNAcylation in diabetes and diabetic complications," Expert Review of Proteomics, vol. 10, pp. 365-380, 2013.

[135] Y. Fardini, E. Masson, O. Boudah et al., "O-GlcNAcylation of FoxO1 in pancreatic beta cells promotes Akt inhibition through an IGFBP1-mediated autocrine mechanism," The FASEB Journal, vol. 28, pp. 1010-1021, 2014. 
[136] A. Gupta Rajapakse, X.-F. Ming, J. M. Carvas, and Z. Yang, "O-linked $\beta$-N-acetylglucosamine during hyperglycemia exerts both anti-inflammatory and pro-oxidative properties in the endothelial system," Oxidative Medicine and Cellular Longevity, vol. 2, no. 3, pp. 172-175, 2009.

[137] H. Goldberg, C. Whiteside, and I. George Fantus, "O-linked $\beta$ $\mathrm{N}$-acetylglucosa mine supports p38 MAPK activation by high glucose in glomerular mesangial cells," The American Journal of Physiology: Endocrinology and Metabolism, vol. 301, no. 4, pp. E713-E726, 2011.

[138] V. V. Lima, K. Spitler, H. Choi, R. C. Webb, and R. C. Tostes, "O-glcnacylation and oxidation of proteins: is signalling in the cardiovascular system becoming sweeter?” Clinical Science, vol. 123, no. 8, pp. 473-486, 2012.

[139] J. L. McLarty, S. A. Marsh, and J. C. Chatham, "Posttranslational protein modification by O-linked $\mathrm{N}$-acetylglucosamine: its role in mediating the adverse effects of diabetes on the heart," Life Sciences, vol. 92, no. 11, pp. 621-627, 2013.

[140] Z. Gurel, K. M. Sieg, K. D. Shallow, C. M. Sorenson, and N. Sheibani, "Retinal O-linked N-acetylglucosamine protein modifications: implications for postnatal retinal vascularization and the pathogenesis of diabetic retinopathy," Molecular Vision, vol. 19, pp. 1047-1059, 2013.

[141] E. D. Schleicher and C. Weigert, "Role of the hexosamine biosynthetic pathway in diabetic nephropathy," Kidney International, Supplement, vol. 58, no. 77, pp. S13-S18, 2000.

[142] R. D. Semba, H. Huang, G. A. Lutty, J. E. Van Eyk, and G. W. Hart, "The role of O-GlcNAc signaling in the pathogenesis of diabetic retinopathy," Proteomics: Clinical Applications, vol. 8, pp. 218-231, 2014.

[143] B. Feng, M. A. Ruiz, and S. Chakrabarti, "Oxidative-stressinduced epigenetic changes in chronic diabetic complications," Canadian Journal of Physiology and Pharmacology, vol. 91, no. 3, pp. 213-220, 2013.

[144] L. Xia, H. Wang, S. Munk et al., "Reactive oxygen species, PKC- $\alpha 1$, and PKC- $\zeta$ mediate high-glucose-induced vascular endothelial growth factor expression in mesangial cells," The American Journal of Physiology: Endocrinology and Metabolism, vol. 293, no. 5, pp. E1280-E1288, 2007.

[145] S. Sasaki and T. Inoguchi, "The role of oxidative stress in the pathogenesis of diabetic vascular complications," Diabetes and Metabolism Journal, vol. 36, no. 4, pp. 255-261, 2012.

[146] L. Xia, H. Wang, S. Munk et al., "High glucose activates PKC$\zeta$ and NADPH oxidase through autocrine TGF- $\beta 1$ signaling in mesangial cells," The American Journal of Physiology: Renal Physiology, vol. 295, no. 6, pp. F1705-F1714, 2008.

[147] Y. Teshima, N. Takahashi, S. Nishio et al., "Production of reactive oxygen species in the diabetic heart: roles of mitochondria and NADPH oxidase," Circulation Journal, vol. 78, pp. 300-306, 2014.

[148] A. Fontayne, P. M.-C. Dang, M.-A. Gougerot-Pocidalo, and J. El Benna, "Phosphorylation of p47phox sites by $\mathrm{PKC} \alpha, \beta \mathrm{II}, \delta$, and $\zeta$ : effect on binding to p22phox and on NADPH oxidase activation," Biochemistry, vol. 41, no. 24, pp. 7743-7750, 2002.

[149] E. A. Bey, B. Xu, A. Bhattacharjee et al., "Protein kinase C $\delta$ is required for $\mathrm{p} 47$ phox phosphorylation and translocation in activated human monocytes," Journal of Immunology, vol. 173, no. 9, pp. 5730-5738, 2004.

[150] K. Naruse, C. Rask-Madsen, N. Takahara et al., "Activation of vascular protein kinase C-beta; inhibits Akt-dependent endothelial nitric oxide synthase function in obesity-associated insulin resistance," Diabetes, vol. 55, no. 3, pp. 691-698, 2006.

[151] K. M. Mellor, M. A. Brimble, and L. M. Delbridge, "Glucose as an agent of post-translational modification in diabetes: new cardiac epigenetic insights," Life sciences, 2014.

[152] S. Lovestone and U. Smith, "Advanced glycation end products, dementia, and diabetes," Proceedings of the National Academy of Sciences of the United States of America, vol. 111, pp. 4743-4744, 2014.

[153] M. A. Queisser, D. Yao, S. Geisler et al., "Hyperglycemia impairs proteasome function by methylglyoxal," Diabetes, vol. 59, no. 3, pp. 670-678, 2010.

[154] P. J. Thornalley, A. Langborg, and H. S. Minhas, "Formation of glyoxal, methylglyoxal and 8-deoxyglucosone in the glycation of proteins by glucose," Biochemical Journal, vol. 344, no. 1, pp. 109-116, 1999.

[155] M. Koga, J. Murai, S. Morita, H. Saito, and S. Kasayama, "Comparison of annual variability in HbAlc and glycated albumin in patients with type 1 vs. type 2 diabetes mellitus," Journal of Diabetes and its Complications, vol. 27, no. 3, pp. 211213, 2013.

[156] N. N. Gholap, M. J. Davies, S. A. Mostafa, and K. Khunti, “Diagnosing type 2 diabetes and identifying high-risk individuals using the new glycated haemoglobin (HbAlc) criteria," British Journal of General Practice, vol. 63, no. 607, pp. e165-e167, 2013.

[157] K. J. Wells-Knecht, E. Brinkmann, M. C. Wells-Knecht et al., "New biomarkers of Maillard reaction damage to proteins," Nephrology Dialysis Transplantation, vol. 11, no. 5, pp. 41-47, 1996.

[158] K. J. Wells-Knecht, D. V. Zyzak, J. E. Litchfield, S. R. Thorpe, and J. W. Baynes, "Mechanism of autoxidative glycosylation: identification of glyoxal and arabinose as intermediates in the autoxidative modification of proteins by glucose," Biochemistry, vol. 34, no. 11, pp. 3702-3709, 1995.

[159] A. Muñoz and M. Costa, "Nutritionally mediated oxidative stress and inflammation," Oxidative Medicine and Cellular Longevity, vol. 2013, Article ID 610950, 11 pages, 2013.

[160] M. R. Hayden and S. C. Tyagi, "Islet redox stress: the manifold toxicities of insulin resistance, metabolic syndrome and amylin derived islet amyloid in type 2 diabetes mellitus," Journal of the Pancreas, vol. 3, no. 4, pp. 86-108, 2002.

[161] H. Vlassara and G. E. Striker, "Advanced glycation endproducts in diabetes and diabetic complications," Endocrinology and Metabolism Clinics of North America, vol. 42, pp. 697-719, 2013.

[162] M. L. Mira, F. Martinho, M. S. Azevedo, and C. F. Manso, "Oxidative inhibition of red blood cell ATPases by glyceraldehyde," Biochimica et Biophysica Acta: Bioenergetics, vol. 1060, no. 3, pp. 257-261, 1991.

[163] S. P. Wolff and R. T. Dean, "Glucose autoxidation and protein modification. The potential role of "autoxidative glycosylation" in diabetes," Biochemical Journal, vol. 245, no. 1, pp. 243-250, 1987.

[164] L. Eiselein, H. J. Schwartz, and J. C. Rutledge, "The challenge of type 1 diabetes mellitus," ILAR Journal, vol. 45, no. 3, pp. 231236, 2004.

[165] V. Bocci, I. Zanardi, M. S. Huijberts, and V. Travagli, "An integrated medical treatment for type-2 diabetes," Diabetes and Metabolic Syndrome, vol. 8, pp. 57-61, 2014.

[166] J. Ye, "Mechanisms of insulin resistance in obesity," Frontiers of Medicine in China, vol. 7, no. 1, pp. 14-24, 2013. 
[167] X. Yang, L. Feng, C. Li, and Y. Li, “Tranilast alleviates endothelial dysfunctions and insulin resistance via preserving glutathione peroxidase 1 in rats fed a high-fat emulsion," Journal of Pharmacological Sciences, vol. 124, pp. 18-30, 2014.

[168] R. P. Robertson, H.-J. Zhang, K. L. Pyzdrowski, and T. F. Walseth, "Preservation of insulin mRNA levels and insulin secretion in HIT cells by avoidance of chronic exposure to high glucose concentrations," Journal of Clinical Investigation, vol. 90, no. 2, pp. 320-325, 1992.

[169] U. Karunakaran and K.-G. Park, "A systematic review of oxidative stress and safety of antioxidants in diabetes: focus on islets and their defense," Diabetes and Metabolism Journal, vol. 37, no. 2, pp. 106-112, 2013.

[170] A. Katsuki, Y. Sumida, H. Urakawa et al., "Increased oxidative stress is associated with serum levels of triglyceride, insulin resistance, and hyperinsulinemia in Japanese metabolically obese, normal-weight men," Diabetes Care, vol. 27, no. 2, pp. 631-632, 2004.

[171] I. Wittmann, J. Nagy, A. Ceriello, and M. Pirisi, "Are insulin resistance and atherosclerosis the consequences of oxidative stress?" Diabetologia, vol. 39, no. 8, pp. 1002-1003, 1996.

[172] G. Paolisso, A. D'Amore, C. Volpe et al., "Evidence for a relationship between oxidative stress and insulin action in non-insulin-dependent (type II) diabetic patients," Metabolism: Clinical and Experimental, vol. 43, no. 11, pp. 1426-1429, 1994.

[173] H. Urakawa, A. Katsuki, Y. Sumida et al., "Oxidative stress ts associated with adiposity and insulin resistance in men," Journal of Clinical Endocrinology and Metabolism, vol. 88, no. 10, pp. 4673-4676, 2003.

[174] Y. Tanaka, C. E. Gleason, P. O. T. Tran, J. S. Harmon, and R. P. Robertson, "Prevention of glucose toxicity in HIT-T15 cells and Zucker diabetic fatty rats by antioxidants," Proceedings of the National Academy of Sciences of the United States of America, vol. 96, no. 19, pp. 10857-10862, 1999.

[175] R. P. Robertson, Y. Tanaka, H. Takahashi, P. O. T. Tran, and J. S. Harmon, "Prevention of oxidative stress by adenoviral overexpression of glutathione-related enzymes in pancreatic islets," Annals of the New York Academy of Sciences, vol. 1043, pp. 513-520, 2005.

[176] T.-A. Matsuoka, Y. Kajimoto, H. Watada et al., "Glycationdependent, reactive oxygen species-mediated suppression of the insulin gene promoter activity in HIT cells," Journal of Clinical Investigation, vol. 99, no. 1, pp. 144-150, 1997.

[177] A. E. Butler, J. Janson, S. Bonner-Weir, R. Ritzel, R. A. Rizza, and P. C. Butler, " $\beta$-cell deficit and increased $\beta$-cell apoptosis in humans with type 2 diabetes," Diabetes, vol. 52, no. 1, pp. 102110, 2003.

[178] S. Pennathur, J. D. Wagner, C. Leeuwenburgh, K. N. Litwak, and J. W. Heinecke, "A hydroxyl radical-like species oxidizes cynomolgus monkey artery wall proteins in early diabetic vascular disease," Journal of Clinical Investigation, vol. 107, no. 7, pp. 853-860, 2001.

[179] P. M. Rindler, C. L. Crewe, J. Fernandes, M. Kinter, and L. I. Szweda, "Redox regulation of insulin sensitivity due to enhanced fatty acid utilization in the mitochondria," The American Journal of Physiology: Heart and Circulatory Physiology, vol. 305, no. 5, pp. H634-H643, 2013.

[180] E. J. Henriksen, M. K. Diamond-Stanic, and E. M. Marchionne, "Oxidative stress and the etiology of insulin resistance and type 2 diabetes," Free Radical Biology and Medicine, vol. 51, no. 5, pp. 993-999, 2011.
[181] P. V. G. Katakam, J. A. Snipes, M. M. Steed, and D. W. Busija, "Insulin-induced generation of reactive oxygen species and uncoupling of nitric oxide synthase underlie the cerebrovascular insulin resistance in obese rats," Journal of Cerebral Blood Flow and Metabolism, vol. 32, no. 5, pp. 792-804, 2012.

[182] K. H. Fisher-Wellman and P. D. Neufer, "Linking mitochondrial bioenergetics to insulin resistance via redox biology," Trends in Endocrinology and Metabolism, vol. 23, no. 3, pp. 142-153, 2012.

[183] J. J. Lemasters and A.-L. Nieminen, "Mitochondrial oxygen radical formation during reductive and oxidative stress to intact hepatocytes," Bioscience Reports, vol. 17, no. 3, pp. 281-291, 1997.

[184] S. Cernea and M. Dobreanu, "Diabetes and beta cell function: from mechanisms to evaluation and clinical implications," Biochemical Medicine, vol. 23, pp. 266-280, 2013.

[185] H. M. Roseman, "Progression from obesity to type 2 diabetes: lipotoxicity, glucotoxicity, and implications for management," Journal of Managed Care Pharmacy, vol. 11, no. 6, supplement, pp. S3-S11, 2005.

[186] E. L. Johnson, "Glycemic variability in type 2 diabetes mellitus: oxidative stress and macrovascular complications," Advances in Experimental Medicine and Biology, vol. 771, pp. 139-154, 2012.

[187] T. Tiganis, "Reactive oxygen species and insulin resistance: the good, the bad and the ugly," Trends in Pharmacological Sciences, vol. 32, no. 2, pp. 82-89, 2011.

[188] J. L. Rains and S. K. Jain, "Oxidative stress, insulin signaling, and diabetes," Free Radical Biology and Medicine, vol. 50, no. 5, pp. 567-575, 2011.

[189] L. Piconi, L. Quagliaro, and A. Ceriello, "Oxidative stress in diabetes," Clinical Chemistry and Laboratory Medicine, vol. 41, no. 9, pp. 1144-1149, 2003.

[190] A. Ceriello, "New insights on oxidative stress and diabetic complications may lead to a "causal" antioxidant therapy," Diabetes Care, vol. 26, no. 5, pp. 1589-1596, 2003.

[191] L.-J. Yan, S.-H. Yang, H. Shu, L. Prokai, and M. J. Forster, "Histochemial staining and qualification of dihydrolipoamide dehydrogenase diaphorase activity using blue native PAGE," Electrophoresis, vol. 28, no. 7, pp. 1036-1045, 2007. 


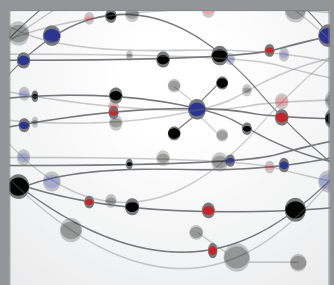

The Scientific World Journal
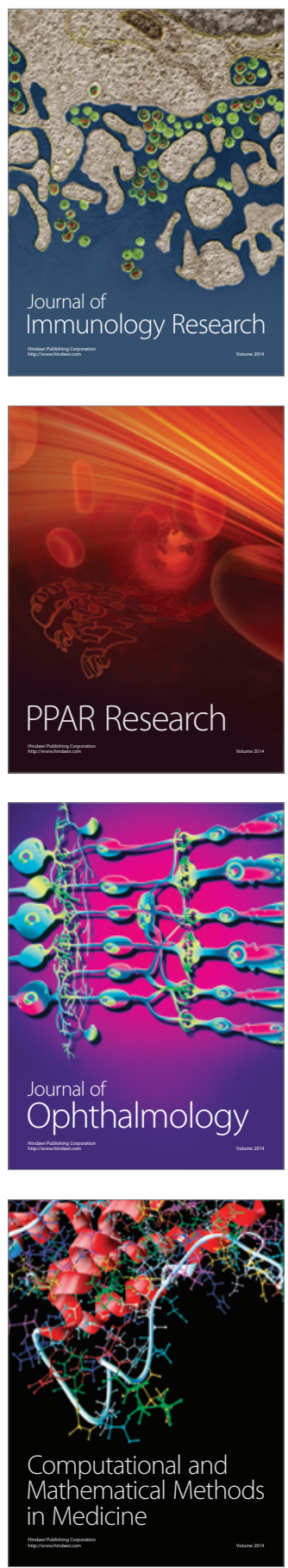

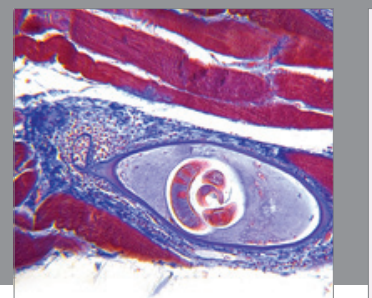

Gastroenterology

Research and Practice
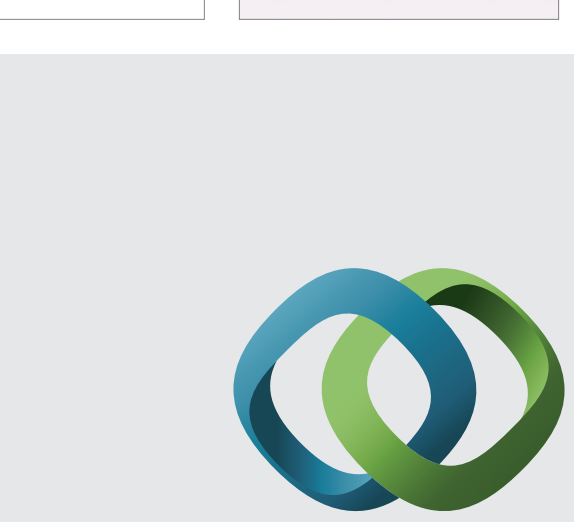

\section{Hindawi}

Submit your manuscripts at

http://www.hindawi.com
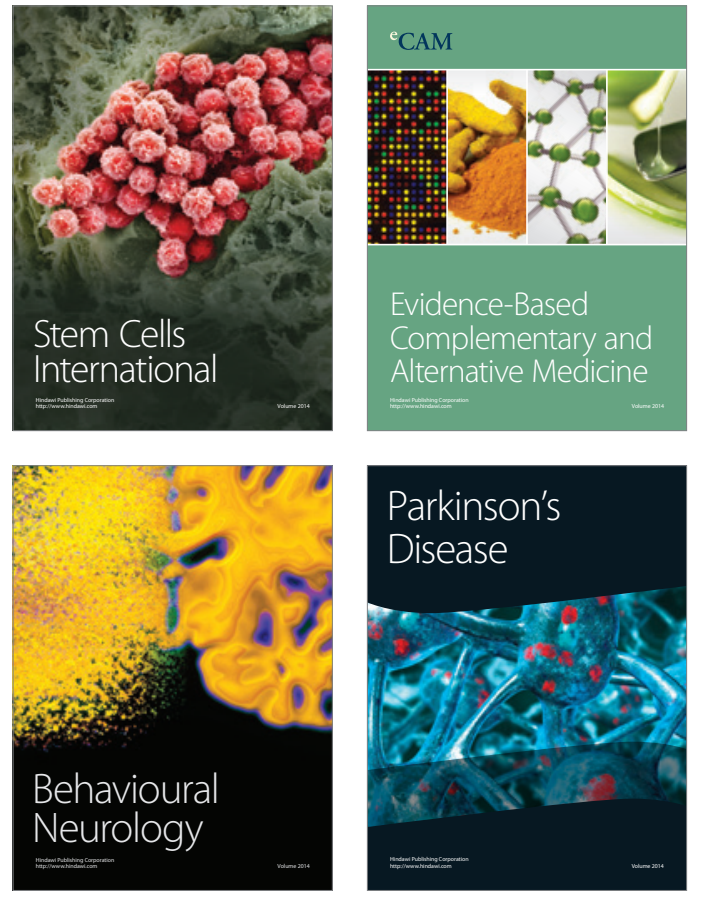
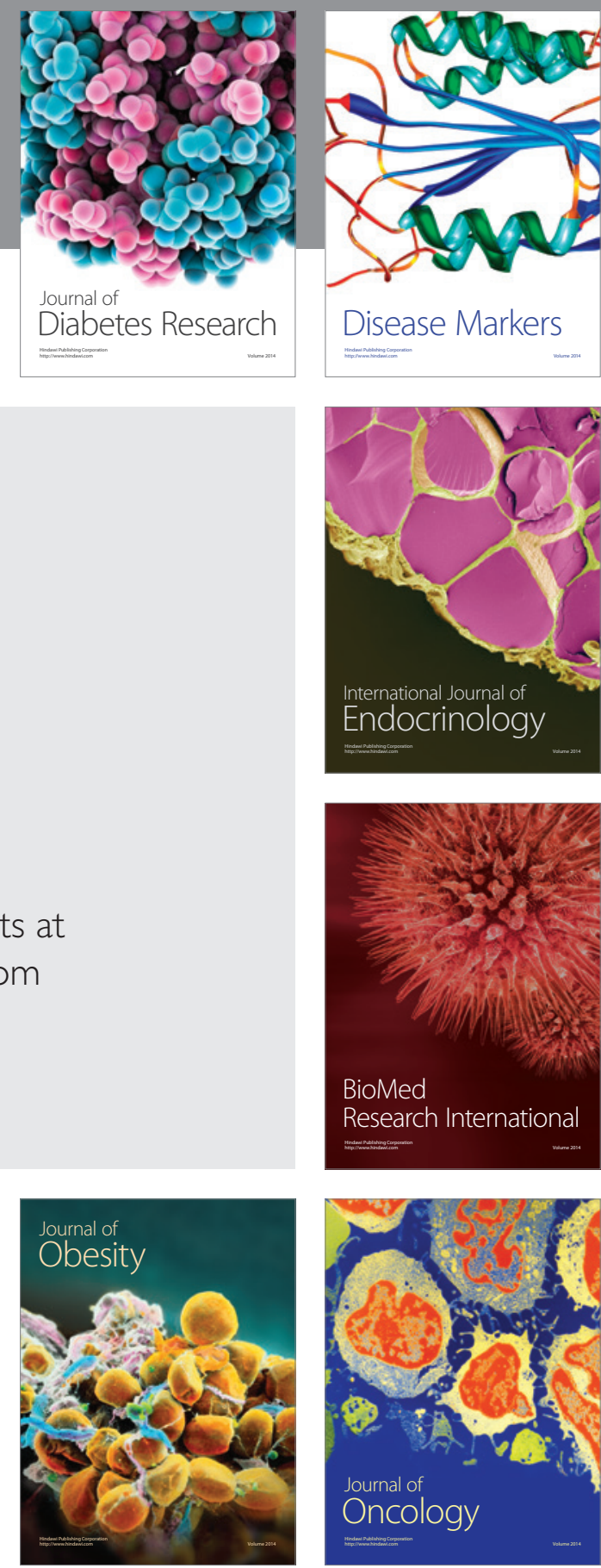

Disease Markers
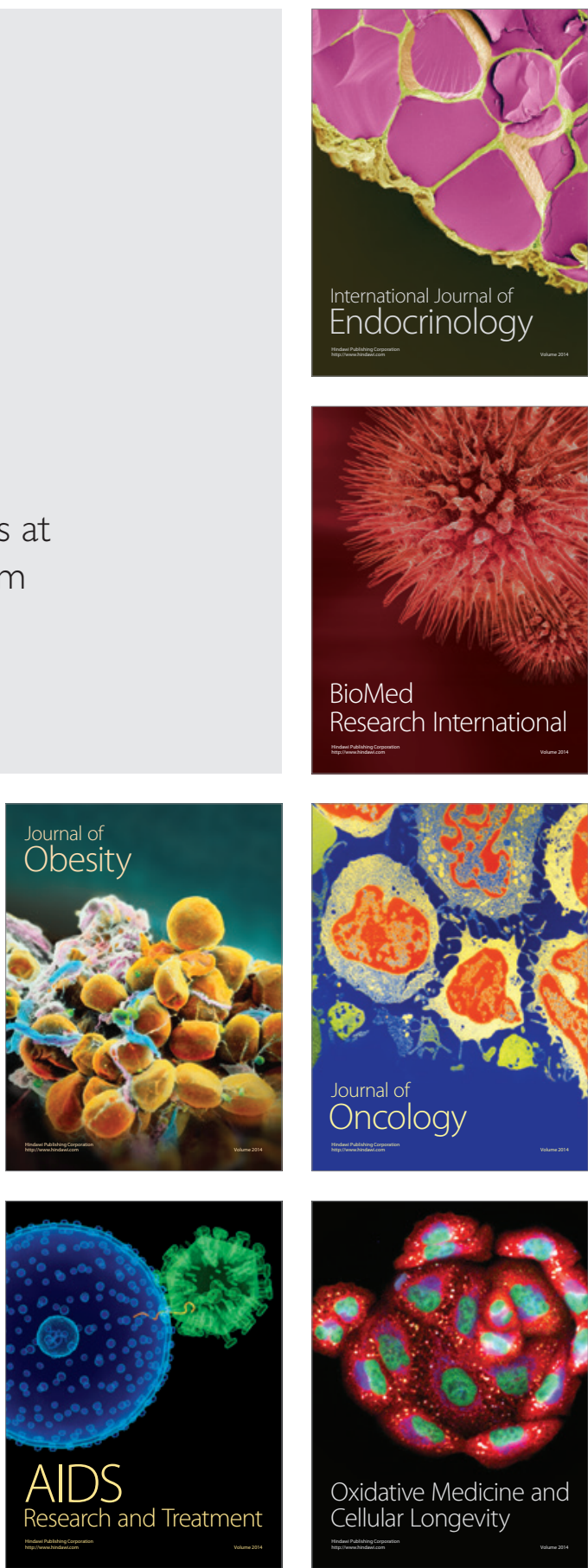